\title{
10-Year Evaluation of Adherence and Satisfaction with Information about Tolvaptan in ADPKD: A Single-Center Pilot Study
}

\section{Holger Schirutschke (iD \\ Peter Gross \\ Alexander Paliege \\ Christian Hugo}

University Hospital Carl Gustav Carus at the Technische, Universität Dresden, Department of Internal Medicine III, Division of Nephrology, Dresden, Germany
Correspondence: Holger Schirutschke University Hospital Carl Gustav Carus at the Technische Universität Dresden, Department of Internal Medicine III, Division of Nephrology, Fetscherstraße

74, Dresden, 01307, Germany

Tel +49-35I-4584233

Fax +49-35I-4585333

Email Holger.Schirutschke@uniklinikumdresden.de
Purpose: Tolvaptan is the only approved drug for the treatment of autosomal dominant polycystic kidney disease (ADPKD) and causes significant polyuria with secondary polydipsia. Up to now, there is no study that examines tolvaptan adherence and satisfaction with information received about tolvaptan in ADPKD patients 10 years after starting tolvaptan therapy.

Patients and Methods: This pilot study includes 12 ADPKD patients that were formerly enrolled in the tolvaptan registration trials and have continued to use tolvaptan thereafter. Data were collected once via questionnaires on patients' self-reported adherence (MARS-D: Medication Adherence Report Scale - German version) and satisfaction with the information received about tolvaptan (SIMS-D: Satisfaction with Information about Medicines Scale German version) at the time of the present study. In addition, serum creatinine levels and clinical data were evaluated.

Results: The MARS-D demonstrated strong adherence to tolvaptan (range of possible score: 5-25; median: 23.5; range of individual results: 5). The SIMS-D showed a high level of satisfaction with the information received about the action and usage of tolvaptan (SIMS-D AU subscale; range of possible score: 0-9; median: 9, range of individual results: 1), but also revealed dissatisfaction regarding the information received about potential problems of tolvaptan in $42 \%$ of the participants (SIMS-D PP subscale; range of possible score: $0-8$; median: 8 , range of individual results: 6$)$. During treatment with tolvaptan, the eGFR decreased from $78.8 \pm 15.9 \mathrm{~mL} / \mathrm{min} / 1.73 \mathrm{~m}^{2}$ to $48.3 \pm 19.4 \mathrm{~mL} / \mathrm{min} / 1.73 \mathrm{~m}^{2}(P<0.0001)$. Conclusion: Although patients reported strong adherence to tolvaptan, there was still dissatisfaction with the information received about potential problems with tolvaptan. Therefore, our data suggest conduction of at least one patient survey on adherence and satisfaction with the information received about tolvaptan during any tolvaptan treatment to improve patient education regarding the use of tolvaptan in slowing down of ADPKD.

Keywords: ADPKD, eGFR, MARS, SIMS, tolvaptan

\section{Introduction}

Autosomal dominant polycystic kidney disease (ADPKD) is the most common inherited renal disorder and the fourth most frequent reason for renal replacement therapy in the world. ${ }^{1,2}$ It is characterized by the formation and continuous expansion of fluid-filled cysts in the kidneys, but extrarenal cysts, intracranial aneurysms, changes in cardiac valves and colonic diverticulosis are also possible. About $85 \%$ of the patients have a mutation in the PKD1 gene and the majority of the others in the PKD2 gene that code for polycystin-1 and polycystin-2, respectively., ${ }^{3,4}$ The clinical 
study program TEMPO (Tolvaptan Efficacy and Safety in Management of Autosomal Dominant Polycystic Kidney Disease and Its Outcomes) proved the efficacy and safety of tolvaptan in the treatment of ADPKD patients. ${ }^{5-7}$ This led to the approval of tolvaptan for the treatment of adults at high risk for rapid progression of ADPKD. Considering the ubiquitous tolvaptan-induced diabetes insipidus renalis as an important side effect during continuous treatment with tolvaptan, patient adherence is strongly challenged but still required for successful long-term therapy. While a high degree of tolvaptan adherence became previously apparent in TEMPO and in the cohort of Edwards et al, ${ }^{6,8,9}$ no study so far specifically targeted adherence of ADPKD patients after a decade of taking tolvaptan. The aim of our work was therefore to assess tolvaptan adherence and satisfaction with information received about tolvaptan in our cohort of 12 ADPKD patients 10 years after the beginning of tolvaptan treatment. Data were collected via the German versions of the Medication Adherence Report Scale (MARS-D) ${ }^{10}$ and the Satisfaction with Information about Medicines Scale (SIMS-D), ${ }^{11}$ which have already been used in other CKD studies. ${ }^{12,13}$ The kidney function decline (assessed by the CKD-EPI eGFR formula), blood pressure and the incidence of complications related to renal cysts (flank pain, macrohematuria, renal cyst infection) were also evaluated.

\section{Patients and Methods Design}

This is an investigator-initiated, non-interventional, monocentric, pilot study in long-term tolvaptan treated ADPKD patients using standardized questionnaires to study therapy adherence and satisfaction with information received about tolvaptan. Our study was approved by the University of Dresden Ethics Committee (Bearbeitungsnummer/Processing number: EK
237062017) and complies with the principles outlined in the Declaration of Helsinki.

\section{Subjects}

From our cohort of tolvaptan-treated ADPKD outpatients, the study enrolled seven males and five females who participated in both the TEMPO 3:4 (3-years, multicenter, randomized, double-blind, placebo-controlled, Phase 3 study; ClinicalTrials.gov Identifier NCT00428948) and the TEMPO 4:4 trial (2-years, open-label extension study; ClinicalTrials.gov Identifier NCT01214421) at the Dresden University Hospital. Only patients belonging to the verum group of TEMPO 3:4 were considered for the present work. Subsequently, all 12 patients received tolvaptan during the open-label evaluation period of TEMPO 4:4 and continued to receive the study drug until the market launch of tolvaptan in Germany in May 2015. The time period of the TEMPO studies is hereinafter referred to as the TEMPO period (Figure 1). After a short tolvaptan-free interval, all patients went on to receive tolvaptan as Jinarc $^{\circledR}$ (Otsuka Pharma $\mathrm{GmbH}$, Frankfurt am Main, Germany) at the same dosage as in the TEMPO studies in the nephrological outpatient clinic of the University Hospital Dresden. Enrollment into the current study took place after detailed information and written informed consent from the study participants. The time period between the start of Jinarc ${ }^{\circledR}$ and the time of the current study is hereinafter referred to as the Jinarc $^{\circledR}$ period (Figure 1). During the $\operatorname{Jinarc}^{\circledR}$ period, regular nephrological check-ups took place every three months in the nephrological outpatient clinic of the University Hospital Dresden. Body weight, blood pressure, medical history and clinical status were recorded. According to the approval regulations of Jinarc $^{\circledR}$, the liver function tests were checked in addition to control of creatinine levels at every visit. The demand of a sufficient drinking habit as

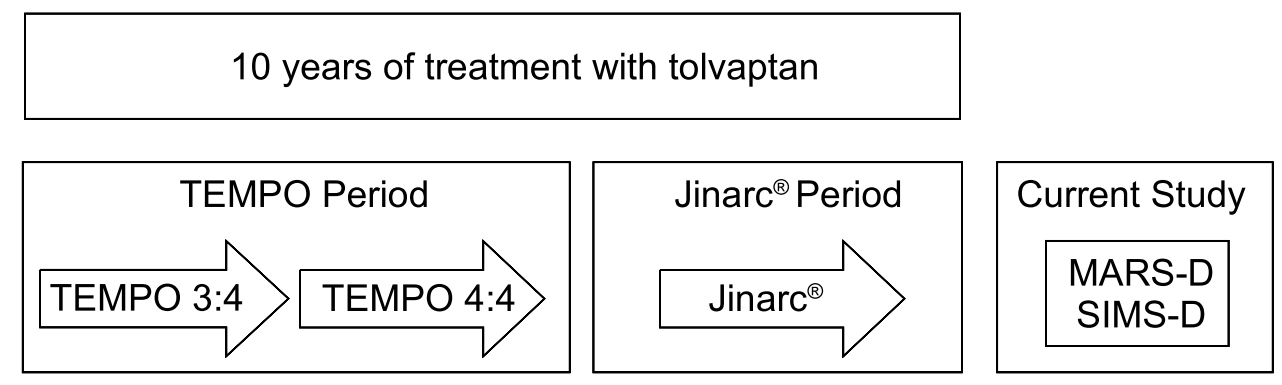

Figure I Flow chart of tolvaptan treatment periods and time of study. Patient self-assessment of adherence and satisfaction with information received about tolvaptan was carried out once at the time of 10 years with tolvaptan treatment using the MARS-D and SIMS-D questionnaires. 
well as a low salt consumption was indicated during each consultation and if necessary, the antihypertensive medication was adjusted. All patients received an MRI for height-adjusted total kidney volume (HtTKV) determination using the Mayo algorithm. ${ }^{14}$

\section{Measurements}

In the current study, at the time of 10 years of treatment with tolvaptan, patients performed a one-time selfassessment of adherence and satisfaction with information received about tolvaptan using the MARS-D and SIMS-D questionnaires (Figure 1). The questionnaires were completed once by the patients immediately after enrollment into the study. The MARS-D ${ }^{10}$ is the German version of the MARS (Medication Adherence Report Scale) ${ }^{15}$ questionnaire and consists of five items describing nonadherent behavior. Patients were asked to score their own behavior regarding the frequency of the different aspects on the following response scales: 'always', "often", "sometimes", "rarely" and "never". Each item is scored with one ("always") to five points ("never"), leading to a sum score ranging between 5 and 25, a higher score indicating higher adherence to the prescribed tolvaptan therapy. The SIMS-D ${ }^{11}$ is the German version of the SIMS (Satisfaction with Information about Medicines Scale) ${ }^{16}$ questionnaire and consists of 17 items. These specify the type of information that patients need for safe and accurate self-management of medication. Patients were asked to rate the drug information they had received on a 5-point scale: "too much," "about right," "too little," "none received," and "none needed." Responses of the items of the SIMS-D: "too much," "too little," and "none received" are counted zero, "about right" and "none needed" are counted one. The evaluation of items 1 to 9 identifies satisfaction with information about "action and usage of medication" (AU subscale, range of possible score: $0-9$ ), evaluation of items 10 to 17 identifies satisfaction with information about "potential problems of medication" (PP subscale, range of possible score: 0-8), a higher score indicating higher satisfaction with the information received about tolvaptan. The kidney function was estimated by the CKD-EPI eGFR formula (CKD-EPI eGFR) expressed as $\mathrm{mL} / \mathrm{min} / 1.73 \mathrm{~m}^{2} .{ }^{17}$ During TEMPO 3:4 and TEMPO 4:4, the respective creatinine levels were measured at the Covance Central Laboratory ServicesGeneva, Switzerland. The results of the creatinine measurements were taken from the TEMPO study files with the permission of Otsuka Pharmaceutical. The change in
eGFR during the TEMPO period was calculated between the end of the tolvaptan dose-escalation period at week 3 of TEMPO 3:4 and the point of the last creatinine determination in TEMPO 4:4. During the Jinarc ${ }^{\circledR}$ period, the creatinine levels were measured at the Institute for Clinical Chemistry and Laboratory Medicine at the University Hospital Dresden, Germany. The change in eGFR during the Jinarc ${ }^{\circledR}$ period was calculated between the time three months after the first prescription of $\operatorname{Jinarc}^{\circledR}$ and the time of the current study. The change in eGFR over the entire period of treatment with tolvaptan was calculated between the end of the tolvaptan dose-escalation period at week 3 of TEMPO 3:4 and the time of the current study. The annual slope of eGFR was calculated for the TEMPO and the Jinarc ${ }^{\circledR}$ period. The difference between the annual slope of eGFR in the TEMPO and the $\operatorname{Jinarc}^{\circledR}$ period was calculated by subtracting the annual slope of eGFR during the TEMPO period from that of the Jinarc ${ }^{\circledR}$ period. Further clinical data on age, sex, prescribed drugs, arterial blood pressure values and complications related to renal cysts were taken from the documentation of the nephrological outpatient clinic and the TEMPO study files with the approval of Otsuka Pharmaceutical. The mean arterial blood pressure was estimated by doubling the diastolic blood pressure, adding the systolic blood pressure and dividing this composite sum by three. We were also interested whether blood pressure and number of antihypertensive drugs would change during the TEMPO and Jinarc ${ }^{\circledR}$ period. Accordingly, the change in mean arterial blood pressure, systolic blood pressure, diastolic blood pressure and the change in the number of antihypertensive drugs during the TEMPO period was calculated between the end of the tolvaptan dose-escalation period at week 3 of TEMPO 3:4 and the point of the last creatinine determination in TEMPO 4:4. The change in mean arterial blood pressure, systolic blood pressure, diastolic blood pressure and the change in the number of antihypertensive drugs during the $\operatorname{Jinarc}^{\circledR}$ period was calculated between the time three months after the first prescription of Jinarc ${ }^{\circledR}$ and the time of the current study.

\section{Statistical Analysis}

Statistical significance was defined as $P<0.05$. Descriptive statistics on categorical data are presented with median, maximum, minimum and range (difference between the largest and smallest value). The sum scores of MARS-D, SIMS-D AU and SIMS-D PP are displayed in frequency diagrams. Metric data are presented as mean with standard deviation. 
The change in eGFR during the TEMPO period, the change in eGFR over the entire period of treatment with tolvaptan, and the change in the annual slope of eGFR between the TEMPO period and the Jinarc ${ }^{\circledR}$ period were analysed using the paired $t$-test after checking for normal distribution with the Kolmogorov-Smirnov test. The change in eGFR during the Jinarc ${ }^{\circledR}$ period was analysed using the Wilcoxon signedrank test after checking for normal distribution with the Kolmogorov-Smirnov test. The correlations of the difference in the annual slope of eGFR between the TEMPO and the Jinarc $^{\circledR}$ period with the change in mean arterial, systolic and diastolic blood pressure during the $\operatorname{Jinarc}^{\circledR}$ period were calculated by using the Pearson correlation.

\section{Results}

General characteristics of the 12 patients are represented in Table 1. The mean change in kidney function over the entire period of treatment with tolvaptan amounted to $-30.5 \pm 10.4 \mathrm{~mL} / \mathrm{min} / 1.73 \mathrm{~m}^{2}(P<0.0001)$. During the entire observation period, none of the patients showed aberrant liver function tests potentially related to tolvaptan. In patient number 9 (marked as \# 9 with $t$ in Table 3 and Figure 3A), the blood pressure could not be adjusted

Table I General Characteristics of the Patients

\begin{tabular}{|l|c|}
\hline $\mathbf{n}$ (Race) & I2 (Caucasian) \\
\hline Female (\%) & $5(41.7)$ \\
\hline Mean age in years (SD) & $49.8(6.6)$ \\
\hline Mean HtTKV in mL/m (SD) & $1023.0(303.9)$ \\
Mean age at Kidney-MRI in years (SD) & $44.4(6.5)$ \\
Median of Irazabal-subclasses* & ID \\
\hline Prevalence of arterial hypertension in \% & 100 \\
Mean age at first diagnosis of arterial & $32.6(9.1)$ \\
hypertension in years (SD) & $2.6(1.2)$ \\
Mean number of antihypertensive drugs (SD) & 100 \\
Angiotensin-converting enzyme inhibitor or & \\
Angiotensin-receptor blocker in \% & $90.0(28.6)$ \\
\hline Mean tolvaptan daily dosage in mg/d (SD) & $10.2(0.3)$ \\
\hline Mean duration of [years (SD)] & $3.0(0.0)$ \\
Cumulative tolvaptan therapy & $3.8(0.3)$ \\
Tolvaptan therapy in TEMPO 3:4 & $3.4(0.2)$ \\
Tolvaptan therapy in TEMPO 4:4 & $0.6(0.2)$ \\
Jinarc ${ }^{\circledR}$ therapy & \\
Tolvaptan interruption between end of & \\
TEMPO 4:4 and first prescription of jinarc ${ }^{\circledR}$ & \\
\hline
\end{tabular}

Note: *Irazabal et al 2015. ${ }^{14}$

Abbreviations: HtTKV, height-adjusted total kidney volume; MRI, Magnetic Resonance Imaging; SD, standard deviation. appropriately due to multiple drug intolerance and the therapy with Jinarc ${ }^{\circledR}$ was stopped at the time of the current study due to CKD stage 5. Detailed characteristics of the 12 patients are represented in Table 3.

\section{Adherence to Tolvaptan}

The MARS-D questionnaire showed a high degree of adherence to tolvaptan with a median count of 23.5 points (range: 5 points). The descriptive statistics of the MARS$\mathrm{D}$ are listed in Table 2. The MARS-D sum score for each patient is shown in Table 3. The distribution of the MARSD sum score is displayed in Figure 2A.

\section{Satisfaction with Information Received about Tolvaptan}

The evaluation of the SIMS-D AU subscale showed a high level of satisfaction with information received about the action and usage of tolvaptan (median sum score: 9 , range: 1). 9 patients (75\%) were completely satisfied with the information received about the action and usage of tolvaptan ( 9 points each) and 3 patients $(25 \%)$ had a sum score of 8 points (Figure 2B).The descriptive statistics of the SIMS-D AU are listed in Table 2. The SIMS-D AU sum score for each patient is shown in Table 3.

The analysis of the SIMS-D PP subscale revealed some dissatisfaction regarding the information received about potential problems with tolvaptan (median sum score: 8 points, range: 6 points). 7 patients (58\%) were completely satisfied with the information received about potential problems of tolvaptan ( 8 points each) but 5 patients $(42 \%)$ had a respective sum score of only $2,3,4,4$ and 6 points (Figure 2C). The descriptive statistics of the SIMS-D PP are listed in Table 2. The SIMS-D PP sum score for each patient is shown in Table 3 .

\section{Change in Kidney Function during Tolvaptan Long-Term Treatment}

Patient number 12 underwent surgical cyst deroofing of the liver after the end of TEMPO 4:4 in 2015 and had to spend two weeks in the intensive care unit due to complications and acute renal failure. This patient (marked as \# 12 with $\dagger$ in Figure $3 \mathrm{~A}$ ) had a $15.5 \mathrm{~mL} / \mathrm{min} / 1.73 \mathrm{~m}^{2}$ reduced eGFR after this event and was therefore excluded from the calculation of the change in mean eGFR. During the entire treatment with tolvaptan, the mean eGFR of the remaining 11 patients decreased from $78.8 \pm 15.9 \mathrm{~mL} / \mathrm{min} /$ $1.73 \mathrm{~m}^{2}$ after the dose-escalation period at week 3 in 
Table 2 Descriptive Statistics of MARS-D and SIMS-D

\begin{tabular}{|c|c|c|c|c|c|c|c|}
\hline \multicolumn{2}{|c|}{ MARS-D (n = I2) } & \multicolumn{6}{|c|}{ Sum score (range of possible score: $5-25$ ) } \\
\hline & & \multicolumn{2}{|l|}{ Median } & Minimum & \multicolumn{2}{|c|}{ Maximum } & Range \\
\hline & & \multicolumn{2}{|l|}{23.5} & 20 & \multicolumn{2}{|c|}{25} & 5 \\
\hline & & \multicolumn{6}{|c|}{$\begin{array}{l}\text { Categorical classification with the corresponding number }(\%) \text { of } \\
\text { patients }\end{array}$} \\
\hline Item & Definition of tolvaptan non-adherence & Always & Often & \multicolumn{2}{|c|}{ Sometimes } & Rarely & Never \\
\hline 1 & Forget the intake & $0(0)$ & $0(0)$ & \multicolumn{2}{|c|}{$0(0)$} & $9(75)$ & $3(25)$ \\
\hline 2 & Change the dosage & $0(0)$ & $0(0)$ & \multicolumn{2}{|c|}{$0(0)$} & I (8) & $11(92)$ \\
\hline 3 & Suspend the intake & $0(0)$ & $0(0)$ & \multicolumn{2}{|c|}{$0(0)$} & $6(50)$ & $6(50)$ \\
\hline 4 & Skip a single dose on purpose & $0(0)$ & $0(0)$ & \multicolumn{2}{|c|}{ I (8) } & $3(25)$ & $8(67)$ \\
\hline 5 & Take less than described & $0(0)$ & $0(0)$ & \multicolumn{2}{|c|}{$0(0)$} & I (8) & $11(92)$ \\
\hline \multirow{4}{*}{\multicolumn{2}{|c|}{ SIMS-D AU (n = I2) }} & & Im scor & rang & of po & ble score & \\
\hline & & Median & & num & Max & & Range \\
\hline & & 9 & & & & & I \\
\hline & & Categorica & assificat & wit & $\begin{array}{l}\text { the } \\
\text { tient }\end{array}$ & respondi & number (\%) of \\
\hline Item & Information received about action and usage of tolvaptan & Too much & $\begin{array}{c}\text { About } \\
\text { right }\end{array}$ & & ittle & $\begin{array}{l}\text { None } \\
\text { received }\end{array}$ & None needed \\
\hline I & What it is called. & $0(0)$ & II (92) & & & $0(0)$ & I (8) \\
\hline 2 & What it is for. & $0(0)$ & II (92) & & & $0(0)$ & I (8) \\
\hline 3 & What it does. & $0(0)$ & II (92) & & & $0(0)$ & I (8) \\
\hline 4 & How it works. & $0(0)$ & II (92) & & & $0(0)$ & I (8) \\
\hline 5 & How long will it take to act. & $0(0)$ & II (92) & & & $0(0)$ & I (8) \\
\hline 6 & How you can tell if it is working. & $0(0)$ & $8(67)$ & & & I (8) & $2(17)$ \\
\hline 7 & How long will you need to be on it. & $0(0)$ & $10(83)$ & & & $0(0)$ & I (8) \\
\hline 8 & How to use it. & $0(0)$ & II (92) & & & $0(0)$ & I (8) \\
\hline 9 & How to get a further supply. & $0(0)$ & II (92) & & & $0(0)$ & I (8) \\
\hline SIMS & $D P P(n=12)$ & & Im scor & rang & of po & ble score & \\
\hline & & Median & & num & $\operatorname{Max}$ & & Range \\
\hline & & 8 & & & & & 6 \\
\hline & & Categorica & assificat & wit & $\begin{array}{l}\text { the } \\
\text { tient }\end{array}$ & respondi & number (\%) of \\
\hline Item & Information received about potential problems of tolvaptan & Too much & $\begin{array}{c}\text { About } \\
\text { right }\end{array}$ & & ittle & $\begin{array}{l}\text { None } \\
\text { received }\end{array}$ & None needed \\
\hline 10 & Whether it has any unwanted side effects. & $0(0)$ & $10(83)$ & & & $0(0)$ & I (8) \\
\hline II & What are the risks of you getting unwanted side effects. & $0(0)$ & $7(58)$ & & & I (8) & I (8) \\
\hline
\end{tabular}

(Continued) 
Table 2 (Continued).

\begin{tabular}{|l|l|c|c|c|c|c|}
\hline 12 & What you should do if you experience unwanted side effects. & $0(0)$ & $10(83)$ & I (8) & $0(0)$ & I (8) \\
\hline 13 & Whether you can drink alcohol whilst taking it. & $0(0)$ & $9(75)$ & I (8) & I (8) & I (8) \\
\hline 14 & Whether it interferes with other medicines. & $0(0)$ & $7(58)$ & $4(33)$ & $0(0)$ & I (8) \\
\hline 15 & Whether it will make you feel drowsy. & $0(0)$ & $7(58)$ & $3(25)$ & I (8) & I (8) \\
\hline 16 & Whether it will affect your sex life. & $0(0)$ & $7(58)$ & $2(17)$ & $2(17)$ & I (8) \\
\hline 17 & What you should do if you forget to take a dose. & $0(0)$ & $10(83)$ & I (8) & $0(0)$ & I (8) \\
\hline
\end{tabular}

Abbreviations: MARS-D, Medication Adherence Report Scale - German version; SIMS-D, Satisfaction with Information about Medicines Scale - German version; AU, action and usage subscale; PP, potential problems subscale.

TEMPO $3: 4$ to $48.3 \pm 19.4 \mathrm{~mL} / \mathrm{min} / 1.73 \mathrm{~m}^{2}$ at the time of the current study $(P<0.0001)$. There was also a significant decrease of the mean eGFR from week 3 in TEMPO 3:4 to $62.7 \pm 17.8 \mathrm{~mL} / \mathrm{min} / 1.73 \mathrm{~m}^{2}$ at the end of TEMPO $4: 4$ (TEMPO period, $P<0.0001$; Figure $3 \mathrm{~A}$ ). Three months after the first prescription of $\operatorname{Jinarc}^{\circledR}$, the mean eGFR amounted to $61.74 \pm 19.3 \mathrm{~mL} / \mathrm{min} / 1.73 \mathrm{~m}^{2}$ and decreased also significantly to the time of the current study (Jinarc ${ }^{\circledR}$ period, Figure $3 \mathrm{~A}, P=0.001$ ). Patients number 9 (marked as \# 9 with $\ddagger$ in Figure $3 \mathrm{~A}$ ) and number 10 (marked as \# 10 in Figure 3A) had the worst kidney function at the end of the TEMPO and the Jinarc ${ }^{\circledR}$ period and were probably in the most progressive stage of ADPKD. Patient number 12 was prescribed Jinarc $^{\circledR}$ in 2016 at a stable general condition and was therefore re-included for the calculation of the annual slope of eGFR. The mean annual slope of eGFR was $-2.7 \pm 1.3 \mathrm{~mL} / \mathrm{min} / 1.73 \mathrm{~m}^{2}$ per year during the TEMPO period and $-4.5 \pm 2.6 \mathrm{~mL} / \mathrm{min} / 1.73 \mathrm{~m}^{2}$ per year during the $\operatorname{Jinarc}^{\circledR}$ period $(P=0.08$; Figure $3 \mathrm{~B})$ where patients number 1 to 4 (marked as \# 1, \#2, \# 3 and \# 4 in Figure 3) experienced a pronounced decrease. In fact, there was a correlation of the difference in the annual slope of eGFR between the TEMPO and the Jinarc ${ }^{\circledR}$ period with the change in mean arterial $(r=0.60 ; P=0.04)$, systolic $(r=0.72 ; P=0.01$; Figure $3 \mathrm{C}$ ) but not diastolic blood pressure during the $\operatorname{Jinarc}^{\circledR}$ period $(r=0.23 ; P=$ 0.47). The respective arterial blood pressure values and total number of anti-hypertensive drugs of each patient are listed in Table 3.

\section{Urological Events during Treatment with Tolvaptan}

7 patients (58\%) reported urological complications since the beginning of TEMPO 3:4. The urological events of each patient are listed in Table 3.

\section{Discussion}

Although tolvaptan has specific side effects and is not primarily essential for survival, a high degree of adherence to tolvaptan therapy became apparent in the pivotal TEMPO 3:4 and TEMPO 4:4 trials in patients with ADPKD. ${ }^{6,8}$ Therefore, we wanted to assess adherence and satisfaction with the information received about tolvaptan in our ADPKD patients with 10 years of tolvaptan treatment with the MARS-D and SIMS-D questionnaires. To the best of our knowledge, our group of 12 ADPKD patients, with a mean tolvaptan treatment duration of 10.2 years, is the largest reported cohort up to now in this regard. The mean daily dosage of $90 \mathrm{mg}$ tolvaptan corresponded to the average dosage of $95 \mathrm{mg}$ per day in the verum group of TEMPO $3: 4^{6}$ and a median Irazabal-classification of 1D was indicative for the presence of rapidly progressive ADPKD. ${ }^{14}$ Encouragingly, the MARS-D sum score of the patients amounted to 23.5 points (maximum possible score: 25 points), thus demonstrating the consistently high degree of tolvaptan adherence even after 10.2 years of treatment. This result is in line with Edwards et al who reported on a group of ADPKD patients in whom only 1 in 39 patients with more than five years of tolvaptan treatment (group average tolvaptan treatment period: 7.6 years; all subjects participated in at least one tolvatptan trial at the Mayo Clinic - USA) discontinued tolvaptan due to an adverse event. ${ }^{9}$ The evaluation of the SIMS-D AU subscale resulted in an average of 9 points (maximum possible score: 9 points) with a range of only 1 point, and thus indicated a high level of satisfaction with the information received about the action and usage of tolvaptan. In contrast to the SIMS-D AU, the evaluation of the SIMS-D PP subscale revealed a clearly measurable level of dissatisfaction regarding the information received about potential problems with tolvaptan in $42 \%$ of the patients. Although the overall score of the SIMS-D PP amounted to the 
Table 3 Detailed Characteristics of the Patients

\begin{tabular}{|c|c|c|c|c|c|c|c|c|c|c|c|c|}
\hline Patient Number & $\mathbf{I}$ & 2 & 3 & 4 & 5 & 6 & 7 & 8 & $9 \ddagger$ & 10 & II & $12 \dagger$ \\
\hline $\begin{array}{l}\text { Sex (age at study in } \\
\text { years) }\end{array}$ & m (49) & m (45) & m (47) & $m(4 I)$ & m (53) & m (56) & m (50) & $f(37)$ & $f(60)$ & $f(53)$ & $f(54)$ & $f(52)$ \\
\hline $\mathrm{HtTKV}$ in $\mathrm{mL} / \mathrm{m}$ at & 1155 & 778 & 1155 & 1095 & 712 & 1207 & 1309 & $|46|$ & 599 & 1132 & 483 & 1192 \\
\hline age (years) with & $(45)$ & (4I) & $(43)$ & (35) & (47) & $(5 \mathrm{I})$ & $(45)$ & $(31)$ & (55) & $(45)$ & (49) & $(46)$ \\
\hline Irazabal-subclass $*$ & ID & IC & ID & ID & IC & IC & ID & IE & IB & ID & IB & ID \\
\hline \multirow{2}{*}{$\begin{array}{l}\text { Tolvaptan daily split } \\
\text { dosage (mg/mg) }\end{array}$} & $60 / 30$ & $90 / 30$ & $90 / 30$ & $90 / 30$ & $45 / 15$ & $60 / 30$ & $90 / 30$ & $45 / 15$ & $45 / 15$ & $90 / 30$ & $45 / 15$ & $45 / 15$ \\
\hline & \multicolumn{12}{|c|}{ Months } \\
\hline $\begin{array}{l}\text { Cumulative } \\
\text { tolvaptan therapy }\end{array}$ & 119 & 117 & 119 & 129 & 123 & 122 & 126 & 119 & 124 & 121 & 125 & 119 \\
\hline TEMPO period & 78 & 79 & 79 & 84 & 81 & 83 & 84 & 80 & 87 & 78 & 84 & 78 \\
\hline jinarc ${ }^{\circledR}$ period & 41 & 38 & 40 & 45 & 42 & 39 & 42 & 39 & 37 & 43 & 41 & 41 \\
\hline \multirow{3}{*}{$\begin{array}{l}\text { Gap between } \\
\text { TEMPO and } \\
\text { Jinarc }{ }^{\circledR} \text { period }\end{array}$} & 8 & 11 & 10 & 5 & 7 & 7 & 7 & 7 & 8 & 5 & 7 & 9 \\
\hline & & & & & & & & & & & & \\
\hline & \multicolumn{12}{|c|}{ CKD-EPI eGFR $\left(\mathrm{mL} / \mathrm{min} / 1.73 \mathrm{~m}^{2}\right)$} \\
\hline $\begin{array}{l}\text { Week } 3 \text { in TEMPO } \\
3: 4\end{array}$ & 91.1 & 76.2 & 73.2 & 94.0 & 79.2 & 83.5 & 105.7 & 84.1 & 58.2 & 49.6 & 72.5 & 68.6 \\
\hline End of TEMPO 4:4 & 70.2 & 66.8 & 67.2 & 84.7 & 68.0 & 63.8 & 79.9 & 71.6 & 29.0 & 30.7 & 57.8 & 46.0 \\
\hline $\begin{array}{l}\text { Month } 3 \text { with } \\
\text { Jinarc }^{\circledR}\end{array}$ & 69.0 & 65.4 & 67.0 & 87.7 & 63.3 & 59.7 & 78.8 & 75.1 & 26.2 & 27.0 & 59.9 & 30.5 \\
\hline $\begin{array}{l}\text { Time of study with } \\
\text { Jinarc }^{\circledR}\end{array}$ & 39.9 & 46.3 & 50.3 & 66.1 & 57.8 & 53.4 & 75.3 & 60.0 & 9.9 & 18.7 & 53.9 & 21.0 \\
\hline \multirow{2}{*}{$\begin{array}{l}\text { Difference } \\
\text { between week } 3 \text { in } \\
\text { TEMPO } 3: 4 \text { and } \\
\text { time of study with } \\
\text { Jinarc }{ }^{\circledR}\end{array}$} & -51.2 & -29.9 & -22.9 & -27.9 & -21.4 & -30.1 & -30.4 & -24.1 & -48.3 & -30.9 & -18.6 & -47.6 \\
\hline & \multicolumn{12}{|c|}{ Annual slope of CKD-EPI eGFR $\left(\mathrm{mL} / \mathrm{min} / 1.73 \mathrm{~m}^{2}\right.$ per year) } \\
\hline TEMPO period & -3.5 & -1.8 & -0.9 & -1.3 & -1.7 & -2.9 & -5.1 & -1.9 & -4.2 & -3.0 & -2.2 & -4.1 \\
\hline Jinarc ${ }^{\circledR}$ period & -10.0 & -7.2 & -5.6 & -6.2 & -2.0 & -2.4 & -1.3 & -5.3 & -5.8 & -2.8 & -2.0 & -3.3 \\
\hline \multirow{2}{*}{$\begin{array}{l}\text { Difference between } \\
\text { TEMPO period and } \\
\text { Jinarc }{ }^{\circledR} \text { period }\end{array}$} & -6.5 & -5.4 & -4.7 & -4.9 & -0.3 & 0.5 & 3.8 & -3.4 & -1.6 & 0.2 & 0.2 & 0.8 \\
\hline & \multicolumn{12}{|c|}{$\begin{array}{l}\text { Systolic/diastolic arterial blood pressure }(\mathrm{mmHg}) \\
\text { Mean arterial blood pressure }(\mathrm{mmHg}) \\
\text { [Total number of anti-hypertensive drugs }]\end{array}$} \\
\hline Week 3 in TEMPO & $124 / 82$ & $126 / 87$ & $122 / 86$ & $130 / 87$ & $145 / 86$ & $117 / 76$ & $128 / 84$ & $123 / 85$ & $164 / 87$ & $125 / 80$ & $122 / 76$ & $120 / 70$ \\
\hline \multirow[t]{2}{*}{$3: 4$} & 96 & 100 & 98 & 101 & 106 & 90 & 99 & 98 & 113 & 95 & 91 & 87 \\
\hline & [2] & [2] & [0] & {$[1]$} & {$[1]$} & [3] & {$[\mathrm{I}]$} & {$[1]$} & [3] & [2] & [2] & {$[1]$} \\
\hline
\end{tabular}


Table 3 (Continued).

\begin{tabular}{|c|c|c|c|c|c|c|c|c|c|c|c|c|}
\hline Patient Number & I & 2 & 3 & 4 & 5 & 6 & 7 & 8 & $9 \ddagger$ & 10 & II & $12 \dagger$ \\
\hline End of TEMPO 4:4 & $\begin{array}{c}149 / 83 \\
105 \\
{[3]}\end{array}$ & $\begin{array}{c}142 / 97 \\
112 \\
{[2]}\end{array}$ & $\begin{array}{c}143 / 90 \\
108 \\
{[0]}\end{array}$ & $\begin{array}{c}13 \mid / 83 \\
99 \\
{[1]}\end{array}$ & $\begin{array}{c}138 / 77 \\
97 \\
{[1]}\end{array}$ & $\begin{array}{c}128 / 78 \\
95 \\
{[4]}\end{array}$ & $\begin{array}{c}133 / 79 \\
97 \\
{[1]}\end{array}$ & $\begin{array}{c}122 / 86 \\
98 \\
{[1]}\end{array}$ & $\begin{array}{c}166 / 78 \\
107 \\
{[3]}\end{array}$ & $\begin{array}{c}124 / 90 \\
10 \mid \\
{[2]}\end{array}$ & $\begin{array}{c}122 / 72 \\
89 \\
{[2]}\end{array}$ & $\begin{array}{c}123 / 77 \\
92 \\
{[4]}\end{array}$ \\
\hline $\begin{array}{l}\text { Month } 3 \text { with } \\
\text { Jinarc }^{\circledR}\end{array}$ & $\begin{array}{c}154 / 88 \\
110 \\
{[3]}\end{array}$ & $\begin{array}{c}161 / 93 \\
116 \\
{[2]}\end{array}$ & $\begin{array}{c}154 / 9 \mid \\
112 \\
{[0]}\end{array}$ & $\begin{array}{c}148 / 95 \\
113 \\
{[1]}\end{array}$ & $\begin{array}{c}137 / 78 \\
98 \\
{[1]}\end{array}$ & $\begin{array}{c}144 / 85 \\
105 \\
{[4]}\end{array}$ & $\begin{array}{c}131 / 87 \\
102 \\
{[1]}\end{array}$ & $\begin{array}{c}129 / 9 \mid \\
104 \\
{[1]}\end{array}$ & $\begin{array}{c}161 / 88 \\
112 \\
{[3]}\end{array}$ & $\begin{array}{c}125 / 84 \\
98 \\
{[3]}\end{array}$ & $\begin{array}{c}132 / 80 \\
97 \\
{[3]}\end{array}$ & $\begin{array}{c}135 / 85 \\
102 \\
{[3]}\end{array}$ \\
\hline $\begin{array}{l}\text { Time of study with } \\
\text { Jinarc }^{\circledR}\end{array}$ & $\begin{array}{c}12 \mid / 79 \\
93 \\
{[4]}\end{array}$ & $\begin{array}{c}125 / 82 \\
96 \\
{[3]}\end{array}$ & $\begin{array}{c}134 / 9 \mid \\
105 \\
{[1]}\end{array}$ & $\begin{array}{c}138 / 94 \\
109 \\
{[2]}\end{array}$ & $\begin{array}{c}|3| / 83 \\
99 \\
{[2]}\end{array}$ & $\begin{array}{c}137 / 85 \\
102 \\
{[5]}\end{array}$ & $\begin{array}{c}130 / 80 \\
97 \\
{[1]}\end{array}$ & $\begin{array}{c}129 / 89 \\
102 \\
{[1]}\end{array}$ & $\begin{array}{c}167 / 8 \mid \\
110 \\
{[3]}\end{array}$ & $\begin{array}{c}118 / 84 \\
95 \\
{[3]}\end{array}$ & $\begin{array}{c}135 / 83 \\
100 \\
{[3]}\end{array}$ & $\begin{array}{c}134 / 77 \\
96 \\
{[3]}\end{array}$ \\
\hline $\begin{array}{l}\text { Difference } \\
\text { between week } 3 \text { in } \\
\text { TEMPO 3:4 and } \\
\text { end of TEMPO 4:4 }\end{array}$ & $\begin{array}{c}25 / 1 \\
9 \\
{[1]}\end{array}$ & $\begin{array}{c}16 / 10 \\
12 \\
{[0]}\end{array}$ & $\begin{array}{c}21 / 4 \\
10 \\
{[0]}\end{array}$ & $\begin{array}{l}\mathrm{I}-4 \\
-2 \\
{[0]}\end{array}$ & $\begin{array}{c}-7 /-9 \\
-9 \\
{[0]}\end{array}$ & $\begin{array}{c}1 \mathrm{I} / 2 \\
5 \\
{[1]}\end{array}$ & $\begin{array}{c}5 /-5 \\
-2 \\
{[0]}\end{array}$ & $\begin{array}{c}-1 / 1 \\
0 \\
{[0]}\end{array}$ & $\begin{array}{c}2 /-9 \\
-6 \\
{[0]}\end{array}$ & $\begin{array}{c}-1 / 10 \\
6 \\
{[0]}\end{array}$ & $\begin{array}{c}0 /-4 \\
-2 \\
{[0]}\end{array}$ & $\begin{array}{c}3 / 7 \\
5 \\
{[3]}\end{array}$ \\
\hline $\begin{array}{l}\text { Difference between } \\
\text { month } 3 \text { with } \\
\text { Jinarc }^{\circledR} \text { and time of } \\
\text { study with Jinarc }^{\circledR}\end{array}$ & $\begin{array}{c}-33 /-9 \\
-17 \\
{[1]}\end{array}$ & $\begin{array}{c}-36 /-11 \\
-20 \\
{[1]}\end{array}$ & $\begin{array}{c}-20 / 0 \\
-7 \\
{[1]}\end{array}$ & $\begin{array}{c}-10 /-1 \\
-4 \\
{[1]}\end{array}$ & $\begin{array}{c}-6 / 5 \\
1 \\
{[1]}\end{array}$ & $\begin{array}{c}-7 / 0 \\
-3 \\
{[1]}\end{array}$ & $\begin{array}{c}-1 /-7 \\
-5 \\
{[0]}\end{array}$ & $\begin{array}{c}0 /-2 \\
-2 \\
{[0]}\end{array}$ & $\begin{array}{l}6 /-7 \\
-2 \\
{[0]}\end{array}$ & $\begin{array}{l}-7 / 0 \\
-3 \\
{[0]}\end{array}$ & $\begin{array}{c}3 / 3 \\
3 \\
{[0]}\end{array}$ & $\begin{array}{c}-1 /-8 \\
-6 \\
{[0]}\end{array}$ \\
\hline $\begin{array}{l}\text { Urological events } \\
\text { during tolvaptan } \\
\text { treatment }\end{array}$ & \multicolumn{12}{|c|}{ Absolute incidence } \\
\hline Flank pain & 3 & 0 & I & 2 & 0 & Weekly & 0 & 0 & I & 0 & $2 /$ year & 4/year \\
\hline Macrohematuria & 0 & 0 & 0 & I & 0 & 0 & 0 & 0 & 0 & 0 & 0 & 0 \\
\hline Renal cyst infection & 0 & 0 & 0 & 0 & 0 & 0 & 0 & 0 & I & 0 & 0 & 0 \\
\hline $\begin{array}{l}\text { Questionnaires } \\
\text { (score range) }\end{array}$ & \multicolumn{12}{|c|}{ Sum score } \\
\hline MARS-D (5-25) & 23 & 24 & 24 & 25 & 20 & 21 & 23 & 24 & 24 & 24 & 22 & 23 \\
\hline SIMS-D AU (0-9) & 9 & 9 & 9 & 8 & 9 & 8 & 9 & 9 & 9 & 9 & 9 & 8 \\
\hline SIMS-D PP (0-8) & 8 & 8 & 6 & 2 & 8 & 4 & 8 & 8 & 8 & 3 & 4 & 8 \\
\hline
\end{tabular}

Notes: *Irazabal et al $2015,{ }^{14}$ fend of tolvaptan in patient \# 9 at time of study with Jinarc ${ }^{\circledR}$ due to CKD stage 5 , tpatient \# 12 was excluded from the calculation of the change in mean eGFR.

Abbreviation: HtTKV, height-adjusted total kidney volume.

maximum possible score of 8 points, there was a rather big range of 6 points. In fact, one third of the patients were dissatisfied with the information received about the risk of tolvaptan-related side effects such as drowsiness, sex life impairment, or potential drug interactions. This result suggests that concerns about tolvaptan-related side effects are common in ADPKD patients, even after 10 years of tolvaptan treatment. Notwithstanding, a lack of information about side effects is certainly a missed opportunity to reassure patients, while patients who are concerned anyway may become even more dissatisfied with their situation. Recently, Joly et al reported on baseline results from the ACQUIRE study (ClinicalTrials.gov Identifier NCT02848521) that collects ADPKD-specific healthrelated quality of life and treatment satisfaction data in 385 ADPKD patients ( $45 \%$ of them with tolvaptan treatment). ${ }^{18}$ In ACQUIRE, the mean "global treatment satisfaction" was scored 58, 68, and 67 for CKD stage 1, 2, and 3 with the abbreviated Treatment Satisfaction Questionnaire for Medication (TSQM-9, score range: 0 to 100$).{ }^{19}$ However, 
A

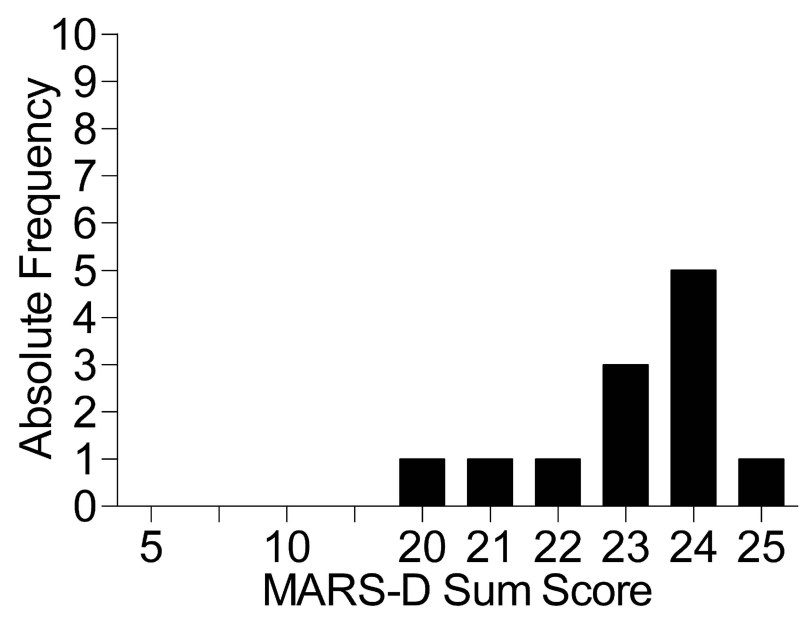

B

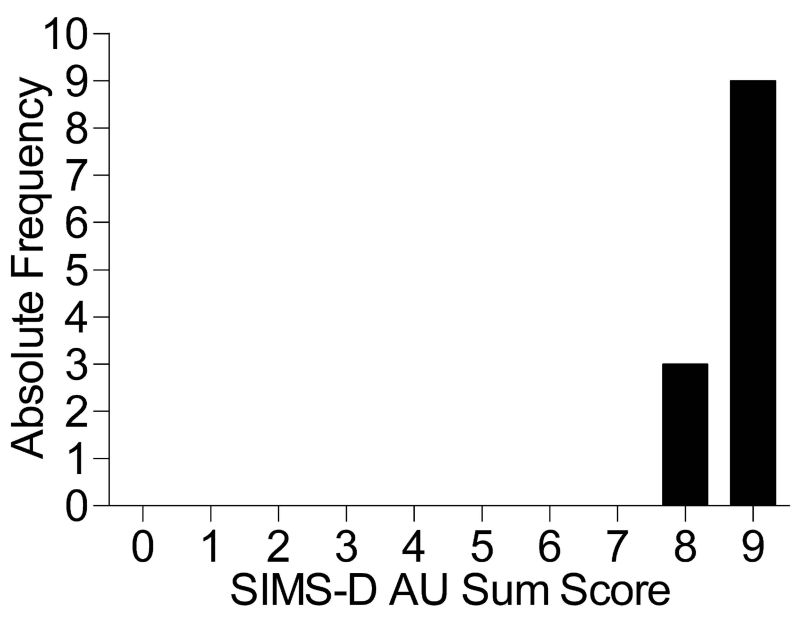

C

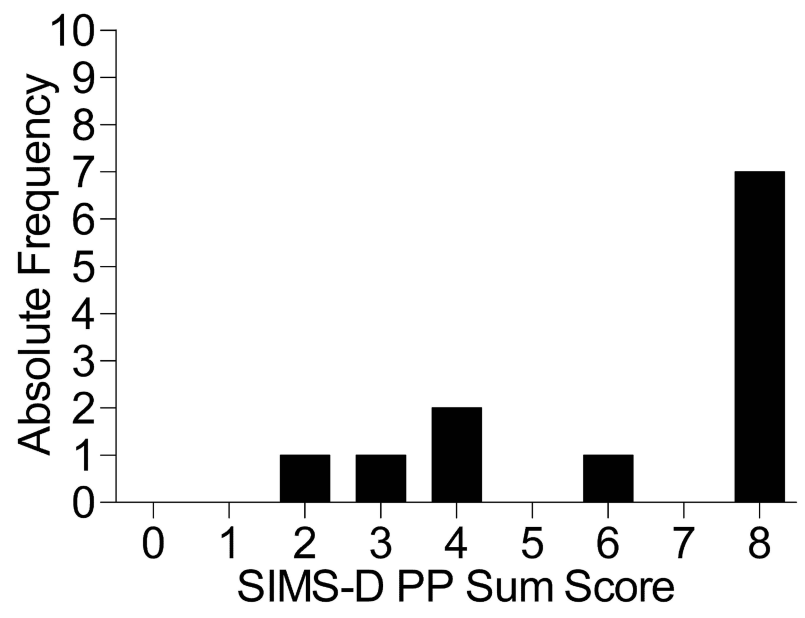

Figure 2 Distribution of the sum scores of the questionnaires. The abscissa scale corresponds to the respective score range. (A) MARS-D (Medication Adherence Report Scale - German version). (B) SIMS-D AU (Satisfaction with Information about Medicines Scale, Action and Usage subscale - German version). (C) SIMS-D PP (Satisfaction with Information about Medicines Scale, Potential Problems subscale - German version). the TSQM-9 neither examines satisfaction with the medical information received nor influence of drug side effects on treatment satisfaction like the original $\mathrm{TSQM}^{20}$ Nevertheless, and in accordance with our results from the SIMS-D PP subscale, a "two-thirds rating" of "global treatment satisfaction" indicates the need for improvement in the care of patients with ADPKD. Unexpectedly, the mean annual slope of eGFR accelerated from $-2.7 \pm 1.3 \mathrm{~mL} / \mathrm{min} /$ $1.73 \mathrm{~m}^{2}$ per year during the TEMPO period to $-4.5 \pm 2.6 \mathrm{~mL} /$ $\min / 1.73 \mathrm{~m}^{2}$ per year during the $\operatorname{Jinarc}^{\circledR}$ period. Recently, Yu et al have shown that the long-term decline of eGFR in ADPKD patients accelerated in later life and was associated with the baseline Irazabal-subclass. ${ }^{21}$ However, this association was not absolutely constant in our small cohort of tolvaptan-treated ADPKD patients, and a detailed examination revealed that an acceleration in the annual slope of eGFR could be observed especially in individuals whose drug therapy for arterial hypertension had to be intensified during the Jinarc $^{\circledR}$ period. For this purpose, the inhibition of the reninangiotensin-aldosterone system (RAAS) was primarily maximized, to which these patients probably reacted particularly sensitively and therefore possibly showed a decrease in eGFR, as has already been reported by Schrier et al in this context. ${ }^{22}$ Accordingly, there was also a significant correlation of the difference in the annual slope of eGFR between the TEMPO and the Jinarc ${ }^{\mathbb{R}}$ period with the change in mean arterial and systolic blood pressure during the Jinarc ${ }^{\circledR}$ period. In view of the small size of our study population, this effect, which probably only occurred in a few patients, may nevertheless have led to a bias in the annual slope of eGFR. We would also like to point out that the results of our pilot study cannot be generalized to all ADPKD patients on tolvaptan therapy, as all of our study participants were extensively supervised during the TEMPO period. However, we wanted to specifically investigate adherence and satisfaction with the information received about tolvaptan in those ADPKD patients who had been on tolvaptan for the longest time. It is therefore entirely possible that ADPKD patients, in whom treatment with tolvaptan was started in clinical practice, are even less satisfied with the information received about the pronounced side effect profile of tolvaptan and may also have less adherence to therapy. The small number of patients, the monocentricity, only one examination during the trial and the fact that adherence was self-reported, are further limitations of our study. As a self-reported study, there may be differences between the actual behavior of patients and what they reported in the MARS-D and future adherence-studies in this 


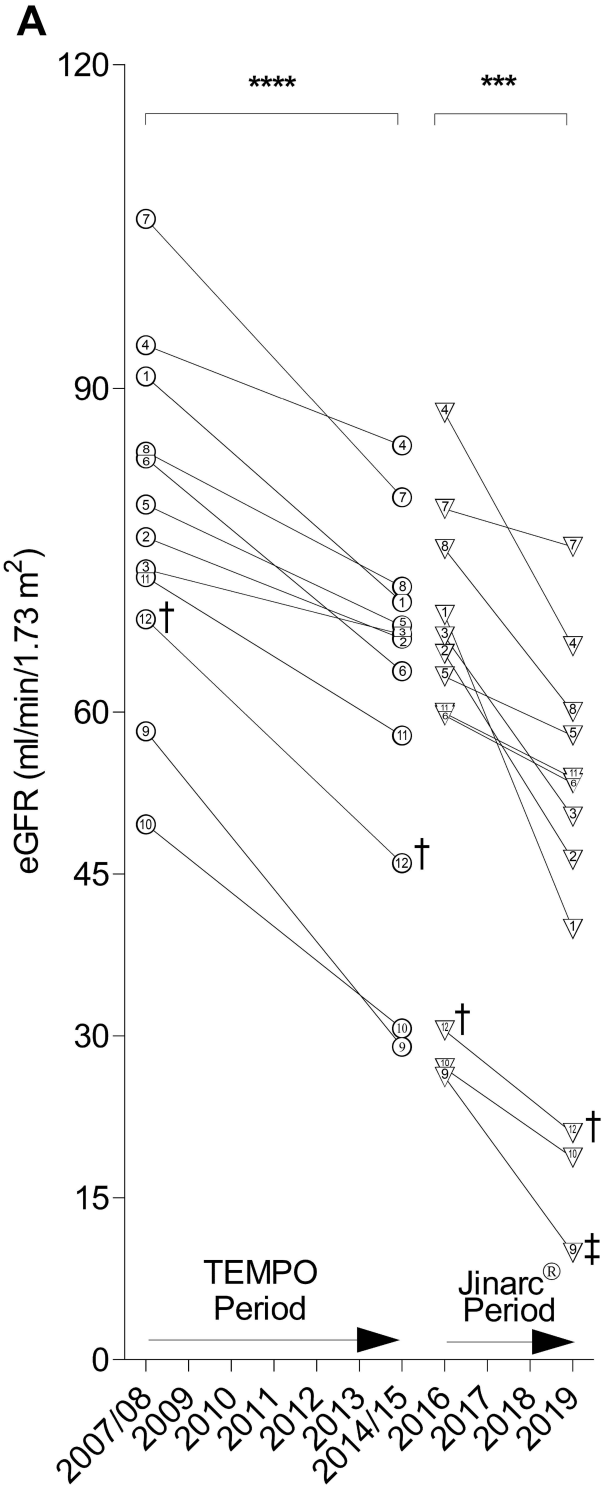

Tolvaptan Therapy
B
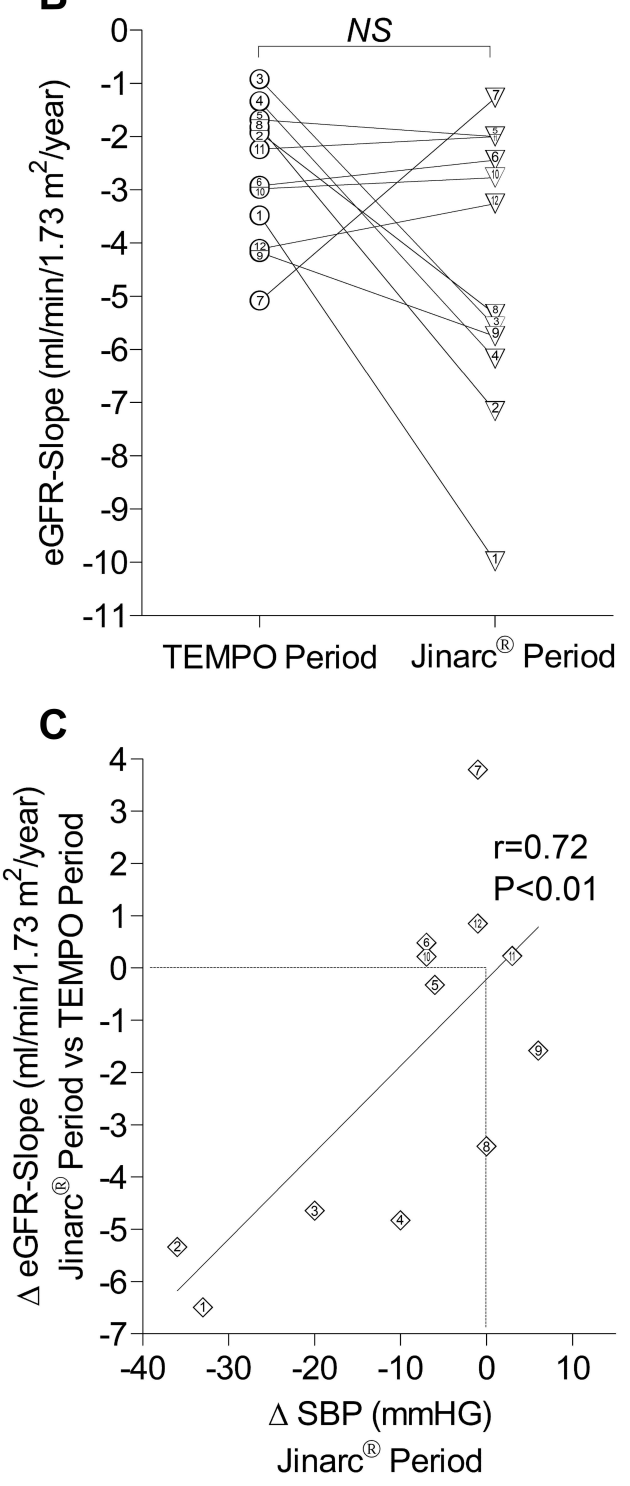

Figure 3 Change in kidney function during tolvaptan long-term treatment. The numbers correspond to the individual patients. (A) Change of eGFR in the TEMPO period between week 3 after dose-escalation of tolvaptan in TEMPO 3:4 and the end of TEMPO 4:4 (****: $P<0.000 \mathrm{I}$ ) and in the Jinarc ${ }^{\circledR}$ period between month 3 with Jinarc ${ }^{\circledR}$ and the time of the current study (***: $P=0.001$ ). $\ddagger$ : End of tolvaptan in patient \# 9 at time of study with Jinarc ${ }^{\circledR}$ due to CKD stage 5 . $\dagger:$ patient \# I2 was excluded from the calculation of the change in mean eGFR. (B) Annualized eGFR-slope during the TEMPO period and the Jinarc ${ }^{\circledR}$ period $(P=0.08, N S)$. (C) Pearson correlation of the difference in the annual slope of eGFR between the TEMPO and the Jinarc ${ }^{\circledR}$ period with the change in mean systolic blood pressure $(\mathrm{SBP})$ during the Jinarc ${ }^{\circledR}$ period $(r=0.72$; $P<0.01)$.

population may need to combine a self-reported measure with other techniques like pill counting.

\section{Conclusion}

Although the patients reported strong adherence to tolvaptan, even after 10.2 years of treatment, there was clearly measurable dissatisfaction with the information received about tolvaptan's side effect profile in $42 \%$ of the patients.
Since tolvaptan has many side effects, it is crucial to validate whether the individual information needs of each patient have really been met. So, in our opinion, the MARS and the SIMS questionnaire could be suitable in clinical practice to ensure that ADPKD patients treated with tolvaptan are as satisfied as possible with this demanding therapy, despite the possible progression of chronic kidney failure. We therefore conclude that at 
least one standardized patient survey on adherence and satisfaction with the information received about tolvaptan should be conducted during any tolvaptan treatment in order to improve patient education regarding the use of tolvaptan in slowing down of ADPKD. This outcome should encourage further trials to define the role of the MARS and the SIMS questionnaire in this context.

\section{Abbreviations}

AU, action and usage of medication subscale of SIMS-D; ADPKD, autosomal dominant polycystic kidney disease; cAMP, cyclic adenosine monophosphate; CKD, chronic kidney disease; CKD-EPI, chronic kidney disease epidemiology collaboration; eGFR, estimated glomerular filtration rate; HtTKV, height-adjusted total kidney volume; MARS-D, Medication Adherence Report Scale - German version; PKD1, polycystic kidney disease 1; PKD2, polycystic kidney disease 2; PP, potential problems of medication subscale of SIMS-D; SIMS-D, satisfaction with Information about Medicines Scale - German version; TEMPO, Tolvaptan Efficacy and Safety in Management of Autosomal Dominant Polycystic Kidney Disease and Its Outcomes trial; TSQM-9, Abbreviated Treatment Satisfaction Questionnaire for Medication.

\section{Data Sharing Statement}

The datasets generated and analyzed during the current study are available from the corresponding author upon reasonable request and with permission of Otsuka Pharmaceutical.

\section{Ethics Approval and Informed Consent}

The study protocol was approved by the University of Dresden Ethics Committee (Bearbeitungsnummer/ Processing number: EK 237062017). The investigation conforms to the principles outlined in the Declaration of Helsinki. The patients were of legal age and able to consent. Enrollment into the study took place after detailed information and written informed consent.

\section{Consent for Publication}

All authors listed have consented to the publication.

\section{Acknowledgments}

The authors thank all participants of the study for their valuable time and selfless commitment. We would also like to thank Professor Rob Horne (C) Rob Horne, School of Pharmacy, University College London, Great Britain) and the Department of General Practice and Health Services Research and Department of Internal Medicine IV, Clinical Pharmacology and Pharmacoepidemiology, University Hospital Heidelberg, Heidelberg, Germany, for providing the MARS-D and SIMS-D.

\section{Author Contributions}

All authors contributed to data analysis, drafting or revising the article, gave final approval of the version to be published, agreed to the submitted journal, and agree to be accountable for all aspects of the work.

\section{Funding}

This investigator-initiated study was supported by Otsuka Pharmaceutical. The funder did not have a role in the design of the study, data collection, analysis, interpretation of data, or in writing the manuscript. Open Access Funding by the Publication Fund of the TU Dresden.

\section{Disclosure}

C.H. reports grants from Otsuka, during the conduct of the study; grants and/or personal fees from Astellas, Sanofi, Genzyme, Roche Pharma, Novartis, and Wyeth/Pfizer, outside the submitted work; P.G. functioned as an investigator in REPRISE until November 2018 (REPRISE ClinicalTrials.gov number, NCT02160145; funded by Otsuka Pharmaceuticals and Otsuka Pharmaceutical Development and Commercialization); H.S. and A. P. declare that they have no competing interests.

\section{References}

1. Torres VE, Harris PC, Pirson Y. Autosomal dominant polycystic kidney disease. Lancet. 2007;369(9569):1287-1301. doi:10.1016/ S0140-6736(07)60601-1

2. Chapman AB, Devuyst O, Eckardt KU, et al. Autosomal-dominant polycystic kidney disease (ADPKD): executive summary from a Kidney Disease: improving Global Outcomes (KDIGO) Controversies Conference. Kidney Int. 2015;88(1):17-27. doi:10.1038/ ki.2015.59

3. Hughes J, Ward CJ, Peral B, et al. The polycystic kidney disease 1 (PKD1) gene encodes a novel protein with multiple cell recognition domains. Nat Genet. 1995;10(2):151-160. doi:10.1038/ng0695-151

4. Mochizuki T, Wu G, Hayashi T, et al. PKD2, a gene for polycystic kidney disease that encodes an integral membrane protein. Science. 1996;272(5266):1339-1342. doi:10.1126/science.272.5266.1339

5. Higashihara E, Torres VE, Chapman AB, et al. Tolvaptan in autosomal dominant polycystic kidney disease: three years' experience. Clin $J$ Am Soc Nephrol. 2011;6(10):2499-2507. doi:10.2215/CJN.03530411

6. Torres VE, Chapman AB, Devuyst O, et al. Tolvaptan in patients with autosomal dominant polycystic kidney disease. $N$ Engl $J$ Med. 2012;367(25):2407-2418. doi:10.1056/NEJMoa1205511 
7. Torres VE, Chapman AB, Devuyst O, et al. Multicenter, open-label, extension trial to evaluate the long-term efficacy and safety of early versus delayed treatment with tolvaptan in autosomal dominant polycystic kidney disease: the TEMPO 4:4 Trial. Nephrol Dialysis Transplant. 2018;33(3):477-489. doi:10.1093/ndt/gfx043

8. Devuyst O, Chapman AB, Shoaf SE, Czerwiec FS, Blais JD. Tolerability of aquaretic-related symptoms following tolvaptan for autosomal dominant polycystic kidney disease: results from TEMPO 3: 4. Kidney Int Rep. 2017;2(6):1132-1140. doi:10.1016/j. ekir.2017.07.004

9. Edwards ME, Chebib FT, Irazabal MV, et al. Long-term administration of tolvaptan in autosomal dominant polycystic kidney disease. Clin J Am Soc Nephrol. 2018;13(8):1153-1161. doi:10.2215/CJN. 01520218

10. Mahler C, Hermann K, Horne R, et al. Assessing reported adherence to pharmacological treatment recommendations. Translation and evaluation of the Medication Adherence Report Scale (MARS) in Germany. J Eval Clin Pract. 2010;16(3):574-579. doi:10.1111/j.13 65-2753.2009.01169.x

11. Mahler C, Jank S, Hermann K, et al. Psychometric properties of a German version of the "Satisfaction with Information about Medicines Scale" (SIMS-D). Value Health. 2009;12(8):1176-1179. doi:10.1111/j.1524-4733.2009.00575.x

12. Hjemås BJ, Bøvre K, Mathiesen L, Lindstrøm JC, Bjerknes K. Interventional study to improve adherence to phosphate binder treatment in dialysis patients. BMC Nephrol. 2019;20:178. doi:10.1186/ s12882-019-1334-x

13. Klewitz F, Nöhre M, Bauer-Hohmann M, et al. Information needs of patients about immunosuppressive medication in a German kidney transplant sample: prevalence and correlates. Front Psychiatry. 2019;10:(JUN):444. doi:10.3389/fpsyt.2019.00444

14. Irazabal MV, Rangel LJ, Bergstralh EJ, et al. Imaging classification of autosomal dominant polycystic kidney disease: a simple model for selecting patients for clinical trials. J Am Soc Nephrol. 2015;26 (1):160-172. doi:10.1681/ASN.2013101138
15. Butler JA, Peveler RC, Roderick P, Horne R, Mason JC. Measuring compliance with drug regimens after renal transplantation: comparison of self-report and clinician rating with electronic monitoring. Transplantation. 2004;77(5):786-789. doi:10.1097/01.TP.00001104 12.20050 .36

16. Horne R, Hankins M, Jenkins R. The Satisfaction with Information about Medicines Scale (SIMS): a new measurement tool for audit and research. Qual Health Care. 2001;10:135-140. doi:10.1136/qhc. 0100135

17. Levey AS, Stevens LA, Schmid CH, et al. A new equation to estimate glomerular filtration rate. Ann Intern Med. 2009;150 (9):604-612. doi:10.7326/0003-4819-150-9-200905050-00006

18. Joly D, Doll H, Sánchez-Covisa J, O'reilly K, Wang-Silvanto J. FP051Baseline results from acquire: a study measuring quality of life, and treatment preference and satisfaction of autosomal dominant polycystic kidney disease patients in Europe. Nephrol Dialysis Transplant. 2019;34(Supplement_1). doi:10.1093/ndt/gfz 106.FP051

19. Bharmal M, Payne K, Atkinson MJ, Desrosiers MP, Morisky DE, Gemmen E. Validation of an abbreviated Treatment Satisfaction Questionnaire for Medication (TSQM-9) among patients on antihypertensive medications. Health Qual Life Outcomes. 2009;7:1-10. doi:10.1186/1477-7525-7-36

20. Atkinson MJ, Sinha A, Hass SL, et al. Validation of a general measure of treatment satisfaction, the Treatment Satisfaction Questionnaire for Medication (TSQM), using a national panel study of chronic disease. Health Qual Life Outcomes. 2004;2:1-13. doi:10.1186/1477-7525-2-12

21. Yu ASL, Shen C, Landsittel DP, et al. Long-term trajectory of kidney function in autosomal-dominant polycystic kidney disease. Kidney Int. 2019;95(5):1253-1261. doi:10.1016/j.kint.2018.12.023

22. Schrier RW, Abebe KZ, Perrone RD, et al. Blood pressure in early autosomal dominant polycystic kidney disease. $N$ Engl $\mathrm{J} \mathrm{Med}$. 2014;371(24):2255-2266. doi:10.1056/NEJMoa1402685
Patient Preference and Adherence

\section{Publish your work in this journal}

Patient Preference and Adherence is an international, peer-reviewed, open access journal that focusing on the growing importance of patient preference and adherence throughout the therapeutic continuum. Patient satisfaction, acceptability, quality of life, compliance, persistence and their role in developing new therapeutic modalities and compounds to optimize clinical outcomes for existing disease states are major areas of interest for the journal. This journal has been accepted for indexing on PubMed Central. The manuscript management system is completely online and includes a very quick and fair peer-review system, which is all easy to use. Visit http:// www.dovepress.com/testimonials.php to read real quotes from published authors. 